\title{
Why Does Aristotle Think Bees Are Divine? Proportion, Triplicity, and Order in the Natural World
}

Daryn Lehoux

\begin{abstract}
Concluding his discussion of bee reproduction in book 3 of Generation of Animals, Aristotle makes a famous methodological pronouncement about the relationship between sense perception and theory in natural history. In the very next sentence, he casually remarks that the unique method of reproduction that he finds in bees should not be surprising, since bees have something "divine" about them. Although the methodological pronouncement gets a fair bit of scholarly attention, and although Aristotle's theological commitments in cosmology and metaphysics are well known, scholars have almost universally passed over the comment about bees and divinity in silence. This paper aims to show why that comment is no mere throwaway, and offers an exploration and elaboration of the ways in which divinity operates even at fairly mundane levels in his natural philosophy, as an important Aristotelian explanation for order, proportion, and rationality, even in the lowest of animals.
\end{abstract}

Bees, Aristotle says, are a puzzle. ${ }^{1}$ Where other animals have either two sexes or no sexes at all, bees seem to have a threefold division of some kind: kings, workers, and drones. ${ }^{2}$ As he works through the possibilities for how each of these ranks of bees are generated, a few facts weigh on Aristotle's analysis. For one, bees are a very common insect and one with which humans have had frequent and ongoing interaction. People have long farmed them, manipulated them for economic ends, created and maintained homes for them, moderated conditions in their hives, and generally employed no small expertise in their interactions with these insects. By the time Aristotle comes to give us our earliest extant scientific account of bees, people already know, in short, a fair bit about what it takes to make bees both happy and productive. Not only this, but as an object of description and discussion, bees as a species appear to be second only to humans in the number of pages Aristotle devotes to them in his corpus—-he clearly has a fascination. ${ }^{3}$ And yet, Aristotle tells us, there is a paradox at the heart of all this: we don't yet really have a handle on how it is that bees reproduce. ${ }^{4}$ 
There was no shortage of contemporary thinking on the topic, however, and as Aristotle canvasses the available theories one by one, he offers up evidence for why each is insufficient. Eventually he settles on a tentative — and entirely unique—explanation: one that pleases him greatly, as we shall see, but one in which he does not quite have one-hundred-percent confidence, for various reasons. The list of rejected possibilities is, to the modern eye, a strange one, which serves to highlight the great difficulties posed by the apparent facts as Aristotle's contemporaries knew them.

If we assume that bees reproduce sexually then we need to account for the roles of the three different kinds of bee: are they three different sexes, three different social classes, three different species? Do workers mate with workers to produce workers and drones with drones to produce drones, or is it that workers instead mate with drones to produce all three types? But workers mating with workers or drones with drones makes no sense, says Aristotle, since there is no discernable sex difference from bee to bee, and all mating requires a male and a female, always with observable anatomical differences between. Workers can't mate with drones because workers don't seem to be either male or female. They can't be female since they have stingers, and 'nature does not give weapons for defense to any females'. ${ }^{5}$ And the workers can't be male since 'no males habitually care for their young', which the workers clearly do. Some people seem instead to think that the various castes of bee are spontaneously generated out in the world somewhere and that the workers then go and fetch these larvae and bring them back to the hive. The problem here, Aristotle points out, is that animals only really take the trouble to care for offspring that appears to be their own, 'oikeios', using what may be a technical term to denote what counts as the legitimate 'offspring' of a species in the pseudo-Aristotelian Problems. ${ }^{6}$ Another possible alternative method of generation for bees, Aristotle continues, says that perhaps the various castes of bee are in fact the offspring of other insects, left around in flowers for the workers to collect. Aristotle rules this out too, on the same grounds as the previous possibility. 
What he settles on, for complex evidential reasons that are beyond the scope of the present paper, is a one-of-a-kind means of species preservation, unique in the animal world, where the drones are produced asexually by the workers, and the workers and kings are both produced asexually by kings. This means that workers and kings must have the generative capacity of both the female and the male, as a combination of some sort within each individual — a system of reproduction unique in Aristotle's biology. In some respects this lack of distinct sexes parallels a system of reproduction that Aristotle suspects may be at play for two kinds of fish, the erythrinus and the channa, for whom no males have ever been found. But there are some crucial differences too: for one, erythrini are thought to generate only erythrini and channae to generate channae, whereas king bees (usually) and workers (always) generate something different in kind from themselves: kings generating workers, and workers drones. This system, if he is right, is unparalleled elsewhere in Aristotle's world. ${ }^{7}$

When he is done setting out his ideas on the generation of bees, Aristotle then turns to related animals, wasps and anthrenae. ${ }^{8}$ Although they share a genus with bees, wasps and anthrenae nevertheless do not have the same remarkable method of reproduction. Instead, these other insects reproduce sexually—a much more pedestrian pattern—and this makes sense, Aristotle tells us, because unlike the genus of bees these animals don't have anything divine about them.

What, I want to ask, could Aristotle possibly mean by associating bees with divinity? Aristotle does not generally appeal to the divine over hastily, and one shouldn't assume he means it lightly here. Let's look at his precise wording:

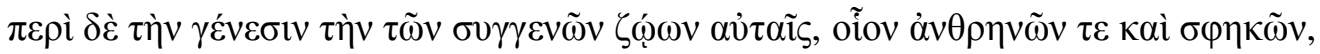

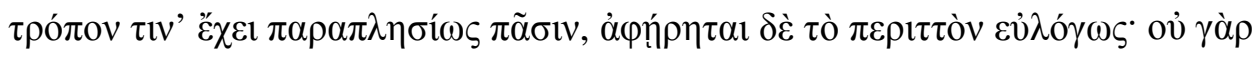

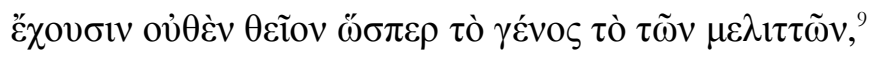

'concerning the generation of animals in the same family as bees, such as anthrenae and wasps, things are in a way similar for all of them, but the unusual aspects are appropriately absent, for they possess nothing divine like the genus of bees does'. 
If he means this in more than a hand-waving fashion (and I hope to show that he does), this is a remarkable claim to find about a common species of animal in the context of Aristotelian natural philosophy. Indeed, Aristotle makes a comparable claim to divinity about no other animal except humans anywhere in his corpus. It will be worth it, then, so see if we can determine what he means by saying that bees possess something divine.

What follows is an exploration into a small corner at the intersection of science and theology, at a very early stage of the history of the life sciences. I want to ask: what ways of seeing, what preconceptions, what priorities were at play when Aristotle looked at bees and tried to understand them? Above all, what kinds of order did he perceive in those insects in particular and what larger themes about the constitution of nature did that order speak to? Religion and science have seen a good deal of productive scholarship of late, and although most of this literature focuses on later periods than our own, we shall see that many of its central interests find reflection at the heart of Aristotelian ideas about life and reproduction. ${ }^{10}$

\section{QUALITIES OF BEES AND OTHER ANIMALS}

An easy answer to the question of how bees could be seen as divine might appear to lie in the general high esteem that ancient writers seem to have had for bees, but the vast majority of evidence for this regard is either later-and often much later- than Aristotle, or else is rooted in mythological or cultic references to bees and their imagery. ${ }^{11}$ Aristotle is not generally one to use folkloric, mythological, or cultic material unreflectively (in fact he is often positively opposed to doing so), and I think it can be shown that something more interesting is afoot in the present case.

In his description of bee generation, Aristotle signals again and again that things are unusual and especially interesting. He repeatedly calls bees and their system of generation

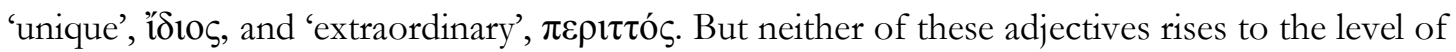


divine (to take a contrasting example, at $H A$ 536a8-11 we see frogs' tongues singled out as unique, `¿ios, without any overtones of divinity implied). When it comes to humans, he only twice calls them divine without qualification, the rest of the time giving humans something like divinity by proxy, which is to say, via some divine property or faculty that Aristotle thinks that humans possess.

Depending on how one reads an important passage of Metaphysics $\Lambda$, where Aristotle is talking about the ability of thought to contemplate thought itself (something he is working up to as a defining characteristic of god), humans, who clearly are capable of reflexive thinking, may also possess this 'divine' ability. ${ }^{12}$ But note that this is a proxy divinity: a person's access to the divine is via the possession of a faculty—reflexive thought—-that is itself divine. Aristotle also tells us that a number of other (often closely related) human faculties are divine: the faculty of reason, the possession of intelligence (voũ $)$, and the ability to think and reflect. Similarly, Aristotle calls our capacity for moral excellence and happiness divine. ${ }^{13}$ In each of these cases, qualities that humans possess are called divine, but not humans in and of themselves.

There are only two places where Aristotle seems to assign divinity directly to humans, which is to say that he gives humans divinity simply by virtue of their humanity. Both occur in the Parts of Animals. In the first of these passages, he says that it is fitting for humans to be the only animal to walk upright, for this is in keeping with our divine essence or substance (ov̉oía). He begins the passage by remarking that in the place where other animals have forelegs and

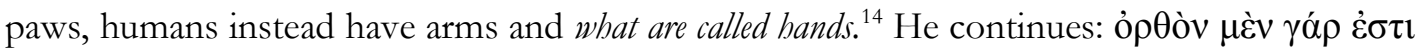

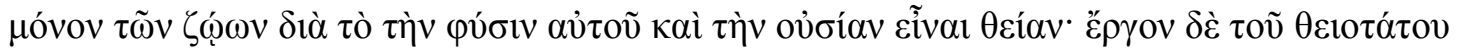

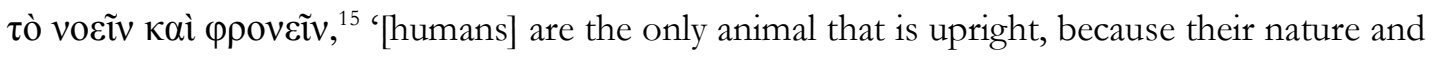
their essence are divine, and also because to think and to be intelligent is the task of the divine'. The idea here is that thinking and intelligence would be impossible if the weight of the body were distributed on all fours as it in other animals, because the bulk of the body would press down on the mind and on the perceptual apparatus. Nature and essence on the one hand, and 
thinking and intelligence on the other, are a one-two punch attesting to human divinity. I will deal with each of these distinct parts of the claim in turn.

The initial attribution in this passage (nature and essence) is clearly direct: we have divinity simply because our nature and our ousia (our being or essence) are divine. The second attribution (via thinking and intelligence) may at first look like the proxy versions of divinity that we saw a moment ago, where divinity arrives via specific faculties that we possess, but the situation is in fact quite the opposite. Consider the structure of the argument, which is not in the first instance trying to prove that humans are divine (this is simply stated in the previous clause), but rather that the divinity of humans (and only humans) explains why they alone walk upright:

(a) Thinking and intelligence are the tasks of what is divine.

(b) Thinking and intelligence are impossible for quadrupeds because of the distribution of body weight, ${ }^{16}$ therefore

(c) Humans, qua animals that are divine both in nature and essence, cannot be quadrupedal.

What is being emphasized here is just an add-on to the assertion, already made, that humans are divine. We are divine and therefore intelligent, and therefore must be bipedal because the distribution of weight in quadrupeds prevents the necessary freedoms for the parts associated with intelligence.

This, then, is the first direct attribution of divinity to humans. In the second one, things

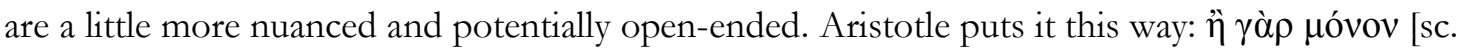

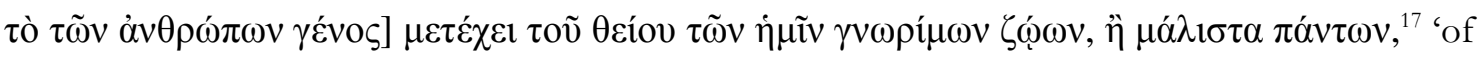
all the animals known to us, either the genus of humans alone partakes of the divine, or [it does so] more than all the others'. The qualification 'more than all the others' is a concession meant to capture something he discusses in the Generation of Animals about the qualities of the souls that all animals (and indeed all living things) possess:

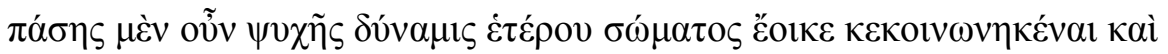

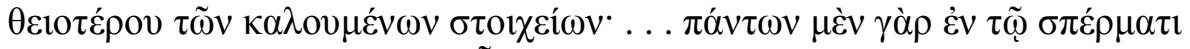

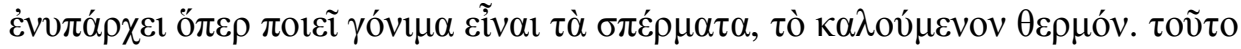

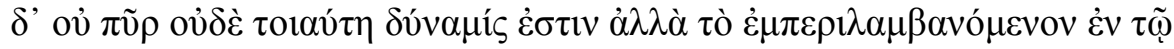




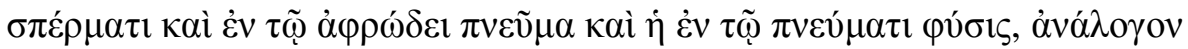

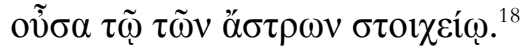

The power of every soul seems to have shared in a different and more divine body than the so-called [four] elements ... For every [animal], what makes the seed generative inheres in the seed and is called its 'heat'. But this is not fire or some such power, but instead the pneuma that is enclosed in the seed and in foamy matter, and the nature in the pneuma, this being analogous to the element of the stars.

So, the generative power of the seed 'shares in' something 'analogous to' the aether, the element of the stars (which is frequently characterized as divine by Aristotle). And this is true for all animals. ${ }^{19}$ Therefore insofar as (most) animals are generated from seed, they have pneuma, and so they all participate to some extent in the divine. This is no mere throwaway comment.

There is a second aspect, however, in which all species participate in the divine. The process of reproduction is said in the De anima to allow each species to continue eternally. Even though this individual snail must perish, the species of snails is a continuity from infinite time past (there was no beginning to the Aristotelian cosmos) and it will continue for infinite time going forward (there is no end). And so, given that it participates in this eternal existence of its own proper species, the individual animal, this individual snail, is participating in the eternal and

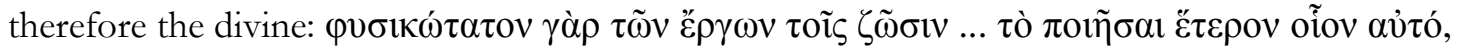

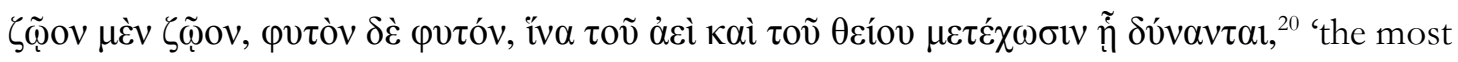
natural activity for animals is the making of another like itself ... an animal [making] an animal and a plant a plant, in order that they may, to the extent that they are able, participate in the eternal and the divine'.

But people_ and bees—are explicitly said to go beyond this basic level. As we have seen, for humans we can parse out from multiple passages what makes them more divine than other animals and the list is not a long one: our possession of reason and nous (mind), our ability to think and understand, and our capacities for moral excellence and happiness. But if we then try to parse out the virtues that Aristotle finds in bees, we never see them qualified in quite these human ways, although in a couple of passages Aristotle may come close. In a perplexing section 
at the very outset of the Metaphysics, Aristotle tells us that bees are 'prudent' or 'wise' (phronimos)

but unable to learn or to hear sounds. ${ }^{21}$ Phronimos as bees may be, though, we note that Aristotle elsewhere calls the deer, the hare, the weasel, and the crane (to whom we shall return in a moment) as well as 'some quadrupeds' phronimos, but he never calls any of these other animals divine. ${ }^{22}$ Similarly, bees, but also 'all animals like them', are said to be more phronimos in their

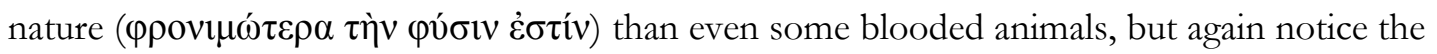
qualifications: bees and others; more than some blooded animals. ${ }^{23}$ Likewise bees and ants are said

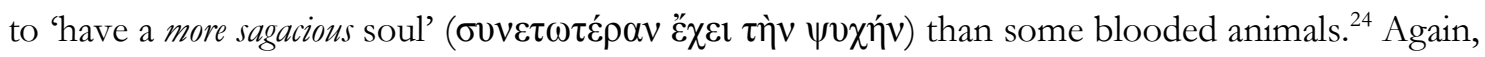
as with the deer and the hare, the ants and 'all other animals like bees' are not called divine.

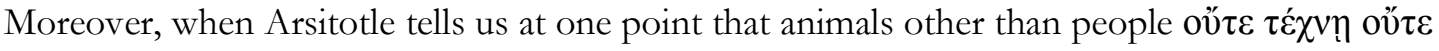

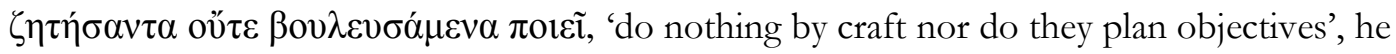
floats two possible outliers to this rule by name, neither of which are bees. He cites instead the spider, the ant, and then adds 'and animals such as these', whatever that may mean. ${ }^{25}$ Finally, he tells us that bees and ants lack phantasia, 'imagination' or 'the faculty of representation', which might be taken to limit, at least somewhat, the extent to which they are phronimos. ${ }^{26}$

Perhaps the most widely discussed of the human-like characteristics that bees are said to possess is their political nature:

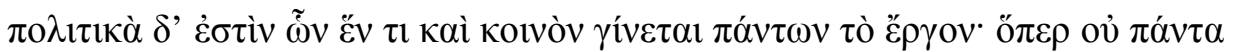

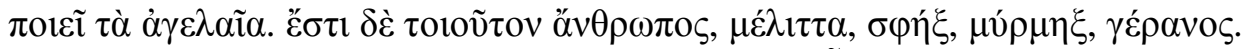

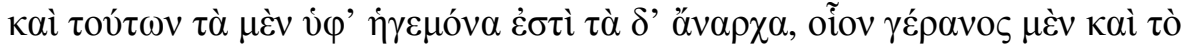

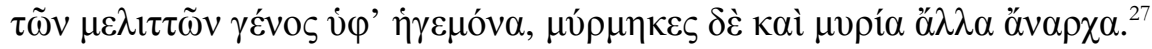

Political animals are those for whom work is common and shared among all; not all gregarious creatures act this way. Animals of [the political] sort are the human, the bee, the wasp, the ant, and the crane. Of these some have a leader and some are unruled. Those with a leader are such as the crane and the genus of bees, while ants and many others are unruled.

Once again, however, bees are far from alone. If we cast about to see what other traits bees may share with some of their fellow political animals we find an interesting list. Like cranes, not only do bees have leaders, they also apportion specific jobs to particular individuals, stationing 
'guards', for example at the openings of their hives. ${ }^{28}$ Cranes do something similar, stationing

them at the outside edges of their flight formations:

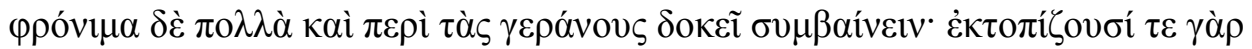

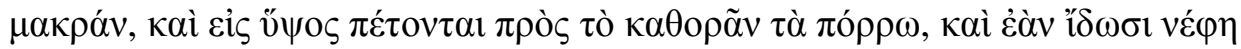

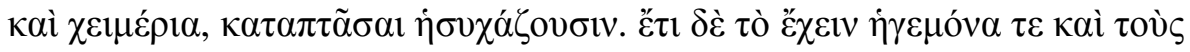

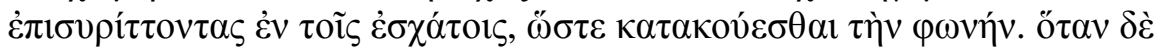

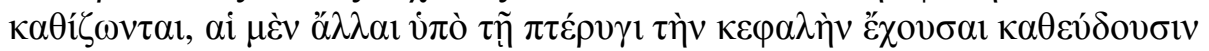

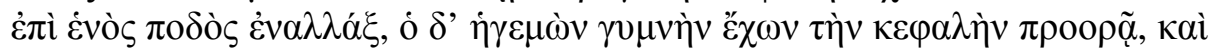

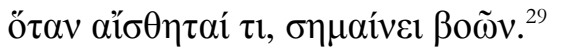

A great deal of phronimos seems to be a characteristic of cranes. They will travel very far, flying high to see great distances and if they see clouds or stormy weather, they fly down and wait it out. They also have a leader, and heralds on the outsides [of their formations] so that their sound may be heard throughout. When they land, the leader, holding its head up, keeps watch while the others sleep on one foot with their heads under their wings. If the leader sees anything, he makes a sign by calling out.

Like the bees that guard the hives, the cranes here post guards at the edges of their flight formations as well as when they sleep. Notice, too, that the action of the leader for alerting the

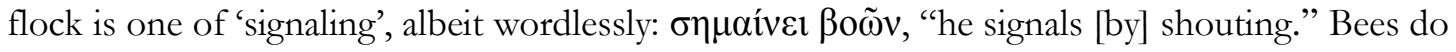
something similar, but rather than alerting the hive to awaken, one of them flies around, buzzing

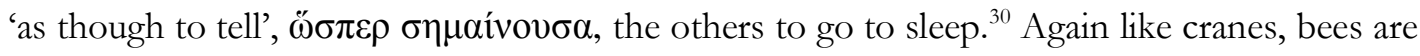

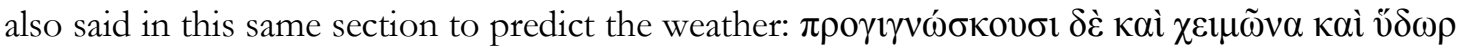
oi $\mu \varepsilon \dot{\lambda} \imath \tau \tau \alpha \iota$, 'bees predict both storms and rain'. ${ }^{31}$ Talk of leaders and signaling may play into a larger set of what appear to be military metaphors for the activity of bees in Aristotle: bees are

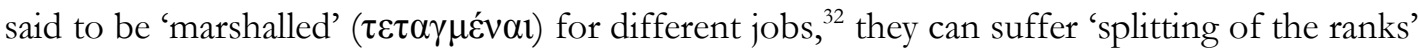
$(\delta 1 \alpha \sigma \pi \tilde{\omega} \sigma \mathrm{l}),{ }^{33}$ and at one point Aristotle tells us a story about one hive invading the other, with an extended use of military language..$^{34}$

If we search around for other virtues and vices attributed to bees, we do not see much that seems to be promising with regard to divinity. It is true that bees are said to be especially

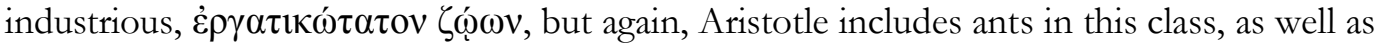
anthrenae, wasps, and all such animals. ${ }^{35}$ Bees are said to be in general 'thrifty', and to store food 


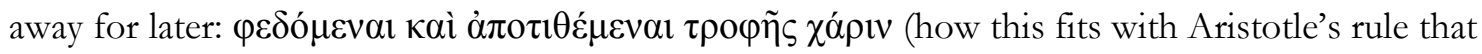
no animals plan for the future, he does not say). ${ }^{36}$ The last of the positive attributes of bees for Aristotle is their cleanliness. They are said to be 'a most clean' animal (I suspect he does not mean the most clean, but Greek can be ambiguous with its superlatives in this way), and he mentions elsewhere that unlike other insects they never settle on rotting flesh. ${ }^{37}$ More negatively, like other political animals, bees and cranes can be violent to each other, ${ }^{38}$ and finally, among bees ('like women', as he feels the need to add) the showy and beautiful ones are lazy: $\alpha \mathbf{i} \delta \grave{\varepsilon}$

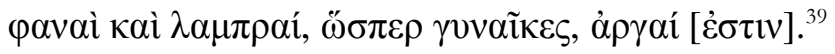

\section{THE DIVINE IN ARISTOTLE}

If we can find nothing specific or in combination in the discussion above that can clearly explain what comprises the divinity of bees, we should perhaps grasp the stick from the other end, and have a look at what kinds of things other than bees are said to be divine in Aristotelian natural philosophy. ${ }^{40}$ In addition to bees, we have already seen humans and (some of) their highest virtues, the generative capacity of seed, and the eternality of species each called 'divine'. And on this last count we might note that the eternal, for Aristotle, is often a-if not the-key aspect of divinity. Indeed, for Aristotle it is immortality that in many instances forms the central attribute

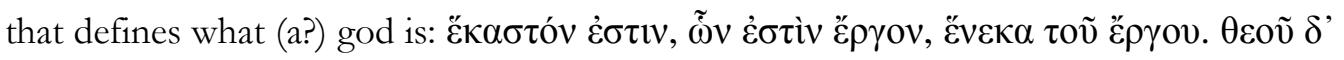

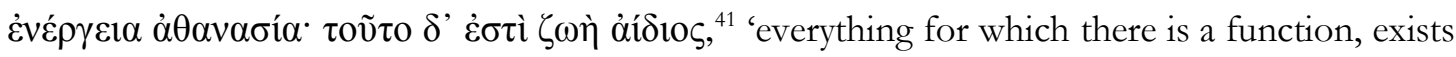
for that function. The activity [actuality] of god is immortality, so the function of god is eternal existence'.

So, too, the fact that the planets move in circles is a key part of what makes the planets and the cosmos as a whole divine in Aristotelian cosmology because circular motion, unlike rectilinear movement, has no beginning and no end. ${ }^{42}$ Anything eternal, whether material or causal, is to that extent divine. ${ }^{43}$ Eternality, though, is not everything for divinity: primacy also seems to play a role, as we find Aristotle assigning divinity to his prime mover, first cause(s), first 
philosophy, and the first or motive principles of physics or philosophy. ${ }^{44}$ None of this, I am afraid, will help us with bees.

Now, we have already seen that bees, like all animals, touch the divine in that they reproduce and maintain the species in eternity. Insofar as they are (non-spontaneouslygenerated) animals, they must also produce seed to generate young and so they contain pneuma in that seed, which again touches them to the eternal and divine matter of the stars, the aether. But this is true of any animal, and thus far there is nothing in the virtues or character of bees in particular that would seem to make them an especially good link with the kinds of things that Aristotle thinks of as divine, and the problem threatens to be a difficult one. As a solution I want to float the following possibility: perhaps it is just the context in which we found Aristotle attributing divinity to bees that offers the solution. That is to say, there is something specific about their mode of generation that links some aspect of the divine to them.

The worry here is that, if we look back to the assertion about bees and divinity that started us on this question, things may well begin to look a little circular with respect to their divinity. But we could structure it as a syllogism thus:

(1) Bees have something divine about them because of how they reproduce.

(2) Wasps do not have anything divine about them as bees do.

Therefore, (3) wasps do not reproduce as bees do.

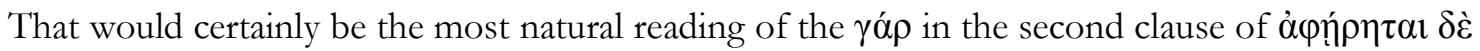

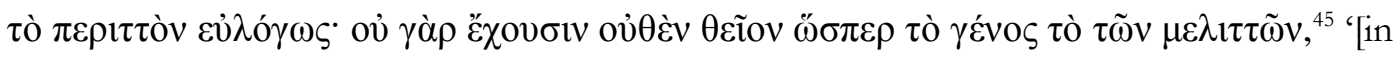
wasps] the unusual aspects are appropriately absent, for they possess nothing divine like the genus of bees does'. This would seem to suggest that the key to bees' divinity may inhere in their threecaste-system for reproduction, one not shared by wasps or other insects. If we look to how Aristotle explains bee reproduction, we find him marveling at two aspects of it in particular: (1) the blending of the sexes in one individual (although he also says that this is at least possibly mirrored by two kinds of fish), and (2) the hierarchy of the castes in their reproductive roles, a feature apparently unique to bees. Let us look at each of these in turn. 
After canvassing all the various theories that people have about bee reproduction and dismissing them, the answer that Aristotle settles on as most likely (on his current evidence) puts the power of both genders into each individual worker bee. This strikes Aristotle as interesting:

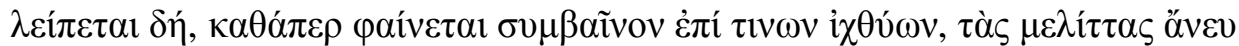

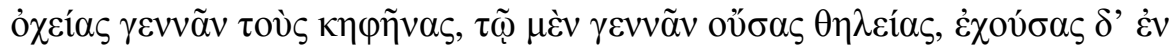

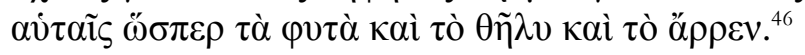

The remaining [possibility] is that workers generate drones without mating, just as appears to be the case with certain fish. With respect to generating they are female but at the same time having in themselves both the male and the female just as plants do.

He goes on to explain that the same principle applies to the kings, which generate both workers and more kings. The comparison to the fish known as the erythrinus and channa, though, is imperfect, as we said above, for each of these fish reproduces themselves rather than producing something different in kind (and this is assuming that Aristotle is correct in his speculation about how those fish reproduce-even he is often tentative when it comes to the erythrinus and channa, since he only has a negative observation to go on: that no males have yet been found). ${ }^{47}$

\section{TRIPLICITY AND PROPORTIONALITY}

And so this blend of male and female is interesting, and at least possibly unique. But what is really unique about bees is their threefold caste system, unseen anywhere else in nature. Not only is it unique in being threefold, but there are also—and this, I think, is the key—several mathematical harmonies in how the reproductive mechanism seems to work across the castes. Notice that the kings produce two kinds of animal: kings and workers, and one class of the animals that they produce, the workers, then goes on to produce one other class of animal, the drones, which then goes on to produce nothing at all, giving us a remarkable (and, Aristotle thinks, very beautiful) two-one-zero progression: kings produce two kinds of offspring, workers produce one, drones produce none (see fig. 1). ${ }^{48}$ 
Moreover, at the two ends of this continuum, we find the kings and drones are each large in size whereas members of the class standing between them (the workers) are small; at the same time, the two generative types (kings and workers) each have stingers while the sterile type (drones) does not (see fig. 2). Aristotle immediately sees a double mathematical beauty to this arrangement, and it is here, I think, that divinity begins to gain a substantial foothold.

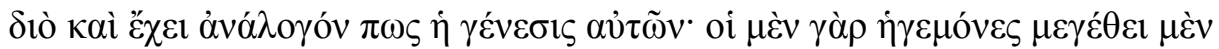

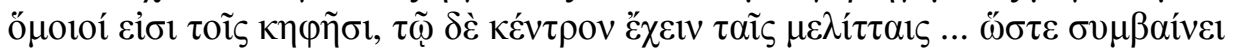

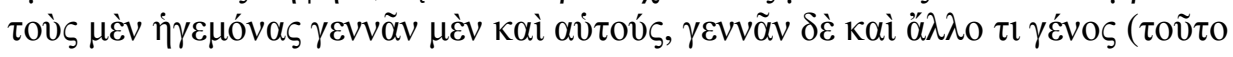

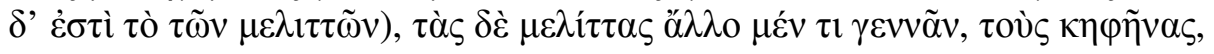

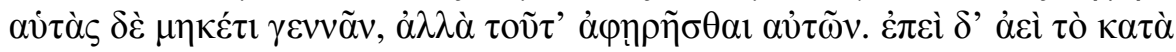

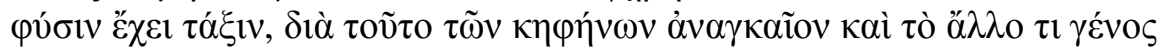

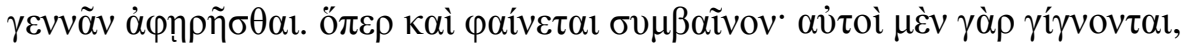

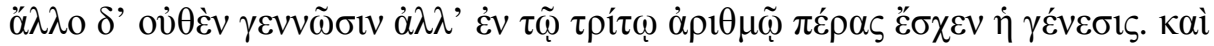

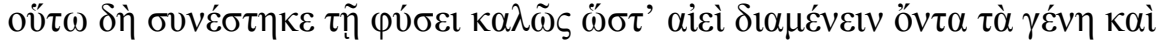

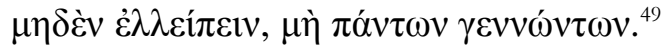

And so there is a kind of proportion to their generation, for the kings are similar to the drones in magnitude, but similar to workers in having a sting ... And also it happens that the kings generate themselves and also generate another kind (i.e., the workers), while the workers generate another kind (the drones) but do not reproduce themselves, for that has been disallowed to them. And since what is according to nature always has an order, for this reason it is necessary that the drones be disallowed to generate another kind, which appears to be the case: they are generated but do not generate anything. And so the generation [of bees] has its completion in the third member of the series and this has been arranged so beautifully by nature that the [three] kinds always persist and never fall short, in spite of the fact that they don't all generate.

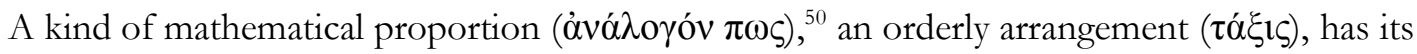

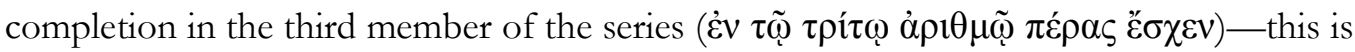
strikingly beautiful (and indeed Aristotle says so explicitly). 


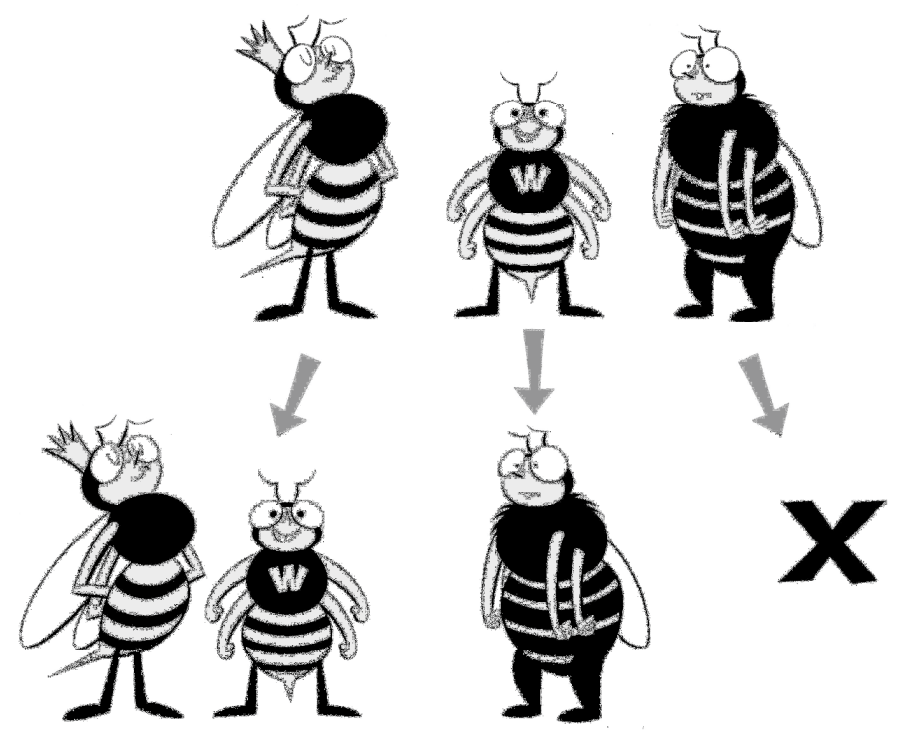

Figure 1:

Aristotle's two-one-zero linear series for bee generation. Aristotle sets the hierarchy up in this order (kings, workers, drones) such that the first member of the series generates itself and the next member, the second member generates the third member, and the third generates nothing. The pattern shows itself not just in terms of descending numbers, but in terms of a descending fecundity which maintains the ordering of the castes at both levels of the diagram.

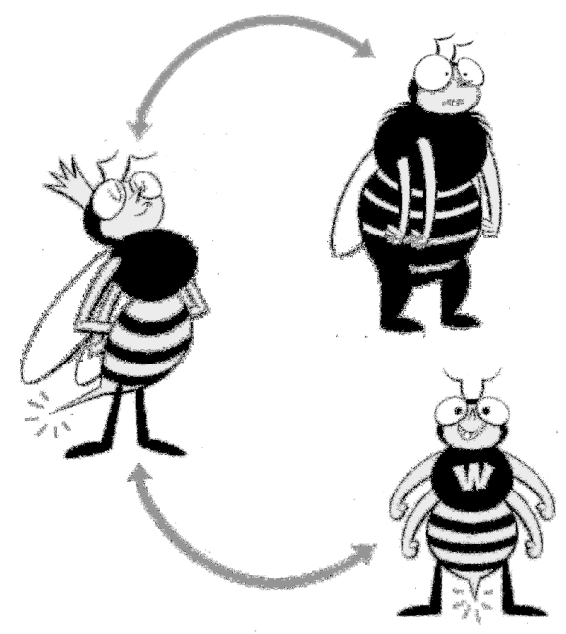

Figure 2:

Parallel proportionalities (size vs. stingers). Note how this centralizes the kings, who have single characteristics in common with each of the other two members of the series, while each of the other two members (workers and drones) are not situated in such a relationship to each other. Rather than reorganizing the earlier hierarchy of kingsworkers-drones, we see here a kind of a transcendence of it. 
But there is one more factor that I suspect is not trivial. It turns out that Aristotle frequently also finds the number three both significant and sublime. For his part, Aristotle is not generally quick to Pythagorize, but we do find him doing so on a few occasions. One such instance occurs at the opening of the De caelo, where he is reflecting on the number of geometrical dimensions possible in our universe, and remarks that the fact that there are three is no accident. For:

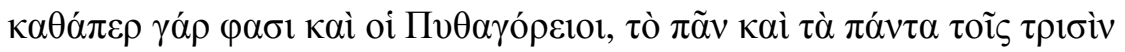

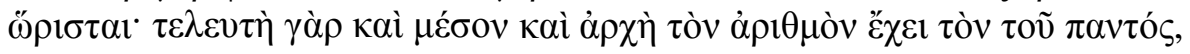

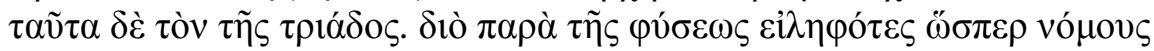

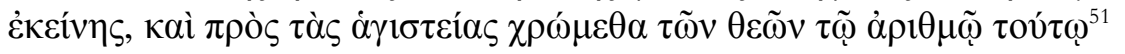

Just as the Pythagoreans say, the whole and all the things [in it] are bound by three; for a beginning, a middle, and an end comprise the number of the whole, which is to say they comprise the number of the triad. And so, taking this fact from nature as one of nature's laws, we also use this number for the worship of the gods.

Threeness takes us effortlessly for Aristotle from the inherent structure of the cosmos, via a law of nature, to the ritual structure of divine worship. It is worth noting that this may be the only instance in the entire Aristotelian corpus where he mentions the Pythagoreans in more than a passing manner without criticizing or correcting them..$^{52}$

As his argument develops in book I of the De caelo, Aristotle again returns to the number three as significant when he finds that the number of simple motions is also three. One has to be an Aristotelian to really buy into this, but on his analysis, there can only exist (1) straight-line motion, (2) circular motion, or (3) a combination of the two. Moreover we see another threeness in the two 'pure' forms of motion, where straight-line motion is defined as always (1) toward a centre, or (2) away from a centre, and circular motion is (3) around a centre. He seems, in the event, particularly pleased that the number of simple motions should match the number of

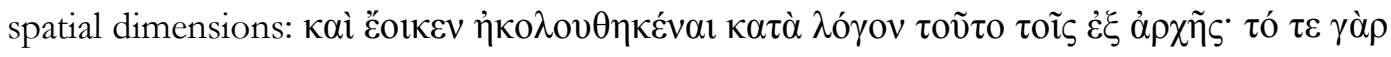

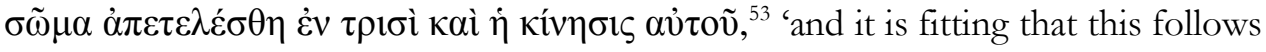


proportionally with what we said at the outset: body is completed in a three, and so is its motion'.

To get a sense of the significance of triplicity for Aristotle, I have combed through the entire corpus of his works to isolate the kinds of things he understands in terms of three explicit parameters, and they turn out to be (a) surprisingly ubiquitous and (b) often quite central to his understanding of the world. What follows is, in spite of its length, necessarily non-exhaustive, partly because he doesn't always flag his triplicities in so many words, and partly because I am bound to have missed a few just by dint of sheer volume. These examples, I should also note, do not count times Aristotle claims that someone else thinks that there are three $x$ 's, nor the frequent instances where he casually offers up triplicities of adjectives or examples as a simple rhetorical figure. What remains, for all that, is truly impressive. ${ }^{54}$ There are:

appetites, three (will, impulse, desire) animal and cosmic parts, three archai of (front/back, above/below, right/left) animal reproduction, a great number of animals reproduce or come to sexual

maturity in intervals of three [months, years], or give birth to three offspring animals, three parts of (parts for food intake, excrement, part in between) argument, three elements of (speaker, subject, audience) attributes, obtain in three ways audience, three kinds of (assemblyman, juror, aficionado)

bodies, three condensed by cold (water, snow, hail) $)^{55}$

coming-to-be, three archai of (two contraries plus a subject of whom they are predicated) 'composition' of animal parts, three kinds of causes/archai, three (form, privation, matter) change, three aspects of (action/passion, combination, contact) change, three kinds of channels, three from eye to brain choice, three objects of (the good, the useful, the pleasant) contempt, three kinds of commerce. three kinds of (capital, transport, sale) constitution, three kinds of courts of law, three determinants for (eligibility, mandate, method of appointment) craftsman, three grades of ${ }^{56}$ deception, three causes of deduction, three terms in demonstration, three divisions of 'by nature' demonstration, three kinds of dimensions (spatial), three 
dispositions, three kinds of (or three grades of emotion or action: the mean, excess, defect)

education, three bases for (the mean, the possible, the proper)

elements (bodily), three (the heavy, the light, the circular) and three elemental

'places'

emotions, three criteria for understanding

excellence (in humans), three sources of (nature, habit, reason) $)^{57}$

friendship, three kinds of

good, three kinds of

government appointments, three considerations for (who appoints, from whom, how)

government, three branches of

government, three forms of

government, three grounds for equality in

governments, three conditions for mixed ones

growth, three properties of ${ }^{58}$

happiness, three means to (excellence, prudence, pleasure)

harms in a partnership, three kinds of

head, three functions for

heart, three actions of (palpitation, pulsation, respiration)

heart, three cavities of

'heaven', three senses of the word

homonymy, three ambiguities in

insect bodies, three parts of

insect development, three stages of

imitation, three kinds of

justice, three forms of (based on three forms of government) ${ }^{59}$

knowing and error, three kinds of

life, three kinds of (the hedonistic, the political, the theoretical or philosophical)

love, three causes of

luck, three determinants of good

magistrates, three offices for choosing

moral states, three to be avoided (vice, intemperance, brutality)

movement, three 'aspects' to (what, where, when), or differently articulated (from

what, to what, what), or differently again (mover, moved, instrument of

motion), or again (mover, moved, time of motion), or again (beginning,

middle, end)

movement, three kinds of (quality, quantity, place)

mover, three kinds of

music etc., three benefits of (education, amusement, contemplation)

non-being, three forms of

nutrition, three aspects to ${ }^{60}$

opposition, three kinds of

orator, three bases for confidence in (prudence, virtue, goodwill)

people, three classes of

perceptibility, three meanings of

perception, three epistemological grades of

persuasion, three forms of (speaker's character, listener's disposition, argument)

physics, three branches of

poetry, three tools of (rhythm, melody, metre)

political offices, three qualifications for highest 
power relations in a household, three kinds of (master-slave, husband-wife, father-children)

presentation, three modes of

problems, three kinds of (ethical, natural, logical)

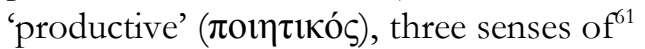

relaxation, three sources of (sleep, drinking, music)

rhetoric, three ends of

rhetoric, three forms of (deliberative, judicial, declamatory)

rhetoric, three grades of proposition in (proof, likelihood, sign)

rhetoric, three temporal horizons relevant to (future, past, present)

sameness, three kinds of

speech, three sources of vividness (metaphor, antithesis, vigour)

speeches, three aspects to (ideas, language, arrangement) ${ }^{62}$

soul, three characteristics of (movement, sensation, incorporeality)

soul, three critical faculties of (phantasia, sensation, nous)

soul, three functions of

soul, three parts that control action and truth (perception, mind, appetite)

soul, three variables in (passions, powers, states)

stasis and revolution, three causes of

substance, three kinds of

'substance', three meanings of (form, matter, combination of the two)

sutures, three in the skulls of male humans (one in females) ${ }^{63}$

theoretical knowledge, three kinds of (mathematics, physiké, theology)

tile, three shapes of to cover a 2-D surface (triangle, square, hexagon)

toes, three joints in

Topics, three ways it will be useful

tyrants, three goals of

voice management, three aspects of (volume, pitch modulation, rhythm)

'voluntary', three senses of (according to appetite, to choice, to thought)

wrongdoing, three aspects to a determination of ${ }^{64}$

Trifurcation clearly plays a major role in Aristotle's conceptual approach to the world. Even if he

does not dwell on the significance of triplicity in the instances listed here, at the very least we can

see an inherent bias toward — or at any rate a strong fondness for-trifurcation. Much more

rarely than these many simple acts of trifurcation, however, Aristotle does also occasionally

comment in a little more detail on why triplicity in itself is important to him.

He tells us, for instance, that three is the first number to which the adjective 'all' applies

(the number two only gives us 'both'). ${ }^{65}$ This is admittedly not much to go on, but the fact that

he feels the need to say it explicitly does indicate something. Going further, however, he also

adds in another context that threeness as an organizing principle is simply and inherently

ubiquitous in the structure of the world. After pointing out that there are 'three' colours in a 


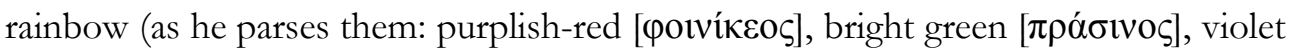

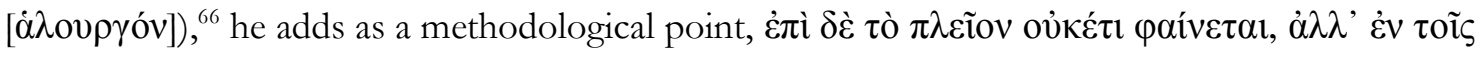

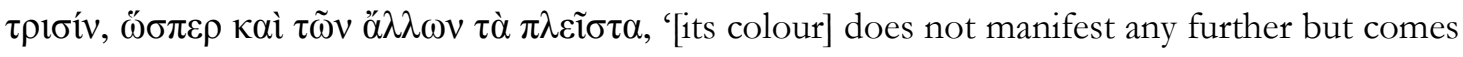
in threes, as most other things also do'. Here we see an explicit acknowledgement that there is something special about three for ordering concepts, and that Aristotle recognizes the pattern that we identified above as a characteristic of his own thinking (even if he does not see it, perhaps, as idiosyncratic).

\section{DIVINE ORDER IN NATURE}

Three, then, manifests as a significant pattern that emerges from the process of ordering phenomena for Aristotle. And ordering, as it turns out, is a quintessential function of the divine,

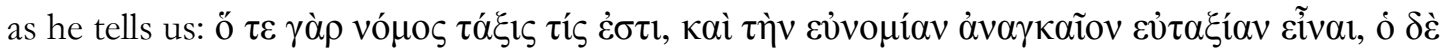

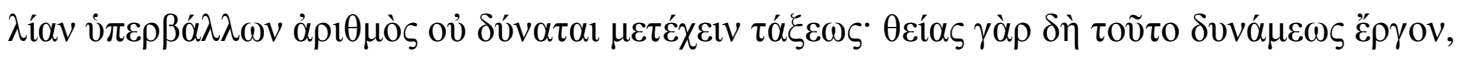

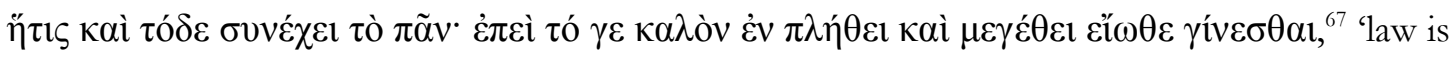
an ordering, and good law must be good order. But an excessive, jumbled number cannot participate in order, for that is the job of the divine power that contains the whole, since what is beautiful [kalos] tends to consist in number and magnitude'. Now, one should be careful no to read too much into the last clause of this claim, the idea that what is beautiful or good consists of number and magnitude, since it is unclear how broadly Aristotle really wants to apply such an argument, but the idea that number and order are themselves attributes and proper actions of divinity seems clear. ${ }^{68}$ Moreover, the passage picks up language Aristotle happened to use in his discussion of size versus fecundity in king bees, where few are produced, but the ones that are, are large. He phrases this in terms of a 'repayment' on the part of nature, where nature takes away from the kings an ability to reproduce many of their kind at once, but repays them with prodigious size. the words he uses for the tradeoff are precisely those he uses to describe beauty 
in the politics passage: it is a balance, a symmetry, between number and magnitude: $\pi \lambda \eta \dot{\theta} \theta \varsigma \tau \varepsilon$

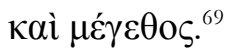

The ethical point in the initial Politics passage is that good laws and good societies reflect a good order among citizens, noncitizen residents, and rulers, and Aristotle parses this order in terms of 'ordered number' explicitly. This may appear at first to be a point of relatively narrow scope, but the broader comparison it draws has much larger significance: divinity acts to give order to the otherwise non-self-ordering mass of the cosmos. Part and parcel of this active ordering is a beauty-relation of number and magnitude. This matters for two reasons. The first is a potential (but only apparent) conflict involving the idea of the beautiful as number for Aristotle. The specific conflict that is threatened has to do with a Pythagorean-Platonist idea that Aristotle flatly rejects elsewhere (at the end of the Metaphysics): the idea that numbers can have causal force. If numbers cannot have causal force for Aristotle, then one might be tempted to argue that one cannot make sense of his statement that the beautiful (a) consists in number, and (b) somehow informs the divinity in ordering the universe. But his argument against the Pythagoreans and Platonists is about how they see particular numbers as final (or even efficient?) causes of unity where Aristotle denies it. Thus, for Aristotle, 'seven' may be shared by the number of musical notes and by the number of stars in the Pleiades, but 'seven' is not a (Platonic) Form whose essence is being instantiated by things both musical and stellar. This is not to say that it is never significant when particular numbers turn up in different applications, but that in such cases it is not the specific number doing the causal work. The number (in the case of bees, three) may show that two different things share important properties, as we saw with the number of spatial dimensions and the number of simple motions, but the number 'three' itself is not causing spatial dimensions and simple motions.

The second reason why the divine act of ordering and its relation to beautiful number and magnitude matters in the present context is because of something Aristotle says about 
mathematics itself. Mathematics, he says, is beautiful—or more to the point: it exhibits the

primary characteristics of beauty, of which, we should not be surprised to learn, there are three.

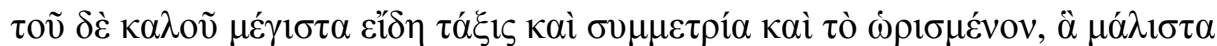

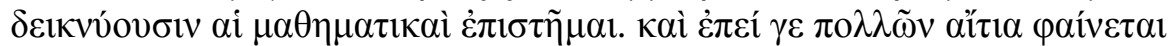

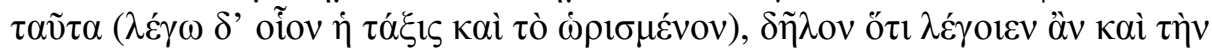

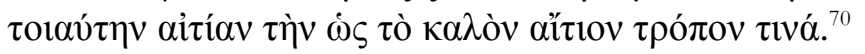

The most important forms of the beautiful are: order, symmetry, and definiteness ${ }^{71}$ which the mathematical sciences show especially. And since these (I mean order and definiteness) seem to be the causes of many things, it is clear that one should speak of this sort of a cause as well: the beautiful as a certain kind of cause.

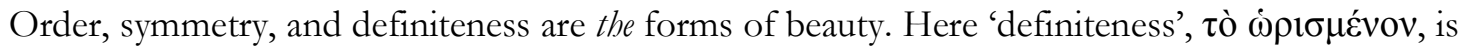
a most interesting word choice: this same word-whose root means to limit or to form a boundary — was used by Aristotle in a passage we saw above to say that 'all things are bound by three'. ${ }^{72}$ And moreover, the language also swings us directly back to Aristotle's discussion of bees once again. Just as we saw a moment ago with number and magnitude, where these qualities are instantiated in the divine order of the cosmos on the one hand, and simultaneously are reflected in the negotiations of nature between size and fecundity in king bees, so too with order, symmetry, and beauty: these terms and concepts play central roles in Aristotle's discussion of bees. If we return now to one of the central passages from earlier in the present investigation, we begin to see Aristotle's description in a much richer light:

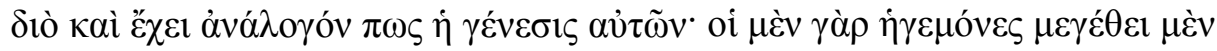

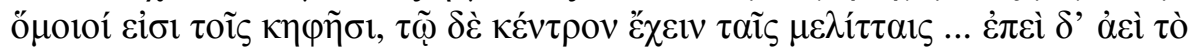

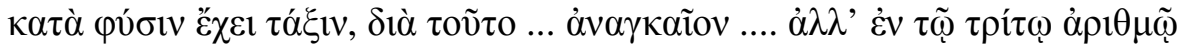

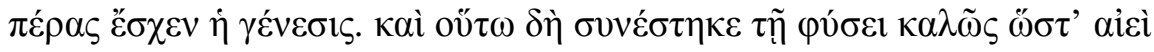

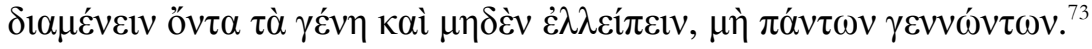

And so there is a kind of proportion to their generation, for the kings are similar to the drones in magnitude, but similar to workers in having a sting ... And since what is according to nature always has an order, for this reason it is necessary .... And so the generation [of bees] has its completion in the third member of the series and this has been arranged so beautifully by nature that the [three] kinds always persist and never fall short, in spite of the fact that they don't all generate.

It is not just that Aristotle uses general language that could be associated with divinity, but that the passage is rich in very specific references to words and concepts that he elsewhere explicitly 
parses as markers of the divine: proportion (symmetry), magnitude, the number three, order, completion (limit, definiteness) — the parallels are really remarkable with the passages on divinity and ordering that we have just seen. And to top it all off? An explicit admission that all of this strikes Aristotle as a very beautiful arrangement for nature to have employed with bees—another of his key words for the divine.

Bees, it would seem, are infested with divinity, even when Aristotle is not yet saying it in so many words. Given the recent attention that historians of science have paid to the roles of theology in guiding how naturalists approach the structure of the world, perhaps this should not be surprising. But at the same time, ever since the Middle Ages, discussions of Aristotle's theology have centred almost exclusively on contexts involving his Prime Mover. What bees show is that broad considerations of divinity inform his thinking on considerably more mundane subjects as well.

\section{Department of Classics and Department of Philosophy Queen's University Kingston, Ont. K7L 3N6 Canada}

lehoux@queensu.ca

\section{Acknowledgments}

I would like to thank Orna Harari, Giora Hon, Yael Kedar, and audiences at Tel Aviv University and the University of Haifa for their comments on earlier drafts of this paper.

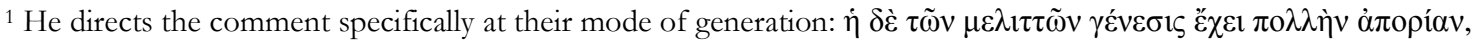
Aristotle, Generation of Animals (hereafter GA) 759a8. All translations are my own unless otherwise indicated. 2 Aristotle calls what we think of as queen bees 'kings.' See, e.g., Rachel D. Carlson, The Honey Bee and Apian Imagery in Classical Literature, Diss., University of Washington, 2015; Robert Mayhew, 'King Bees and Mother Wasps: A Note on Ideology and Gender in Aristotle's Entomology', Phronesis (1999) 44, pp. 127-34; Malcolm Davies and Jeyaraney Kathirithamby Greek Insects, Oxford: Oxford University Press, 1986.

${ }^{3}$ I here follow Aristotle in the use of the terms species and genus, which often differs from modern usage. For Aristotle 'bees' are a species relative to some more general category such as 'animal'. The terms genus and species for him capture something closer to the English logical categories 'general' and 'specific' (which are in any case derived from the Latin genus and species). On volume of Aristotle's references to bees versus humans, see Simon Byl, Recherches sur les grands traités biologiques d'Aristote, Brussels: Académie royale de Belgique, 1975, p. 340.
} 
${ }^{4}$ I add the 'yet' because of the optimism Aristotle seems to indicate as he looks forward to future investigations on bees, in a passage that leads up to the famous methodological pronouncement about how theory must accommodate observation in future investigations, not the other way around (GA 760b27f.).

${ }^{5}$ One assumes (as is indicated by the following clause) that he means 'without also giving such weapons to the males', which the drones (the supposed males in this theoretical scenario) lack. The whole passage is at $G A 759 \mathrm{~b} 1 \mathrm{f}$. On the roles of male vs female in Aristotle, the literature is vast. A good beginning would include Sophia M. Connell, Aristotle on Female Animals, Cambridge: Cambridge University Press, 2016; Robert Mayhew, The Female in Aristotle's Biology, Chicago: University of Chicago Press, 2004; Aryeh Kosman, 'Male and Female in Aristotle's Biology', in James G. Lennox and Robert Bolton (eds.), Being, Nature, and Life in Aristotle, Cambridge, 2010, pp. 14767.

${ }^{6}$ The question in the Problems is why something born from seed counts as an animal's own proper offspring, but something born from the animal's excrement (a spontaneously generated maggot, for example), does not so count: the one is oikeios, and the other not. See Pseudo-Aristotle, Problems 878a1. On the Problems and the Aristotelian corpus generally, see Robert Mayhew (ed.), The Aristotelian Problemata physica, Leiden: Brill, 2015.

${ }^{7}$ See GA 715b16, Aristotle, History of Animals (hereafter HA) 556b22 f., 539b10. For discussion of spontaneous generation and genus see Daryn Lehoux, Creatures Born of Mud and Slime, Baltimore: Johns Hopkins University Press, 2017.

8 Anthrenae is usually translated as 'hornets' although it is unclear what the precise distinction between wasps (sphekes) and anthernae was seen to be. I speculated in Lehoux, op. cit. (7), p. 49 that antbrenae may refer to parasitic wasps rather than stinging wasps. Given the uncertainty, however, I will leave the word untranslated in what follows. ${ }^{9}$ GA 761a2-5.

${ }^{10}$ On religion and science generally, see for example Peter Harrison and Jon H. Roberts (eds.), Science without God? Retbinking the History of Scientific Naturalism, Oxford: Oxford University Press, 2019; Peter Harrison, The Territories of Science and Religion, Chicago: University of Chicago Press, 2015; Daryn Lehoux, What Did the Romans Know? Chicago: University of Chicago Press, 2012; Gary B. Ferngren (ed.), Science and Religion: A Historical Introduction, Baltimore: Johns Hopkins University Press, 2002; John Henry, The Scientific Revolution and the Origins of Modern Science, London: Macmillan, 1997.

${ }^{11}$ On bees in antiquity, see, e.g., Carlson, op. cit. (2); Kenneth F. Kitchell, Animals in the Ancient World from $A$ to $Z$, New York: Routledge, 2014; David Engels and Carla Nicolaye (eds.), Ille operum custos: Kulturgeschicbtliche Beiträge zur antiken Bienensymbolik und ibrer Rezeption, Hildesheim: Olms, 2008; Davies and Kathirithamby, op. cit. (2); Neville Morley, 'Civil War and Succession Crisis in Roman Beekeeping', Historia (2007) 56, pp. 462-70; Ian C. Beavis, Insects and Other Invertebrates in Classical Antiquity, Exeter: Exeter University Press, 1988; Lilian B. Lawler, 'Bee Dances and the "Sacred Bees", The Classical Weekly (1954) 47, pp. 103-6; Arthur Bernard Cook, 'The Bee in Greek Mythology', Journal of Hellenic Studies (1895) 15, pp. 1-24.

${ }_{12}$ Aristotle, Metaphysics (hereafter Metaph.) 1072b23

${ }^{13}$ Reasoning: Aristotle, Eudemian Ethics (hereafter EE) 1248a25 f. voṽc: GA 737a10, Aristotle, De anima (hereafter De an.) 408b29, Metaph. 1074b16; voṽ or 'something else' either divine or the most divine thing in us: Aristotle, Nichomachean Ethics (hereafter EN) 1177a16. Other things (planets, stars) 'more divine' than man: EN 1141b1. People can aspire to the divine: EN 1177b28. Moral excellence: EN 1145a27. Happiness: EN 1099b16-17, 1101b24, 1177a15; EE 1215a17, 1217a28.

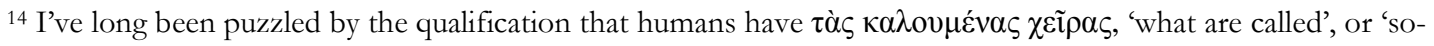
called', hands. I think there may be something interesting to say here but exploring that question is a task for another paper.

15 Aristotle, Parts of Animals (hereafter PA) 686a27-28.

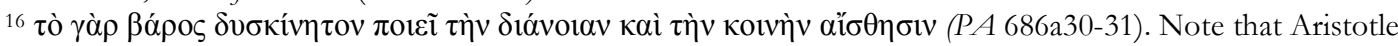
understates a crucial part of the argument: where I have said intelligence is 'impossible' for quadrupeds, Aristotle says merely that 'it is not easy'.

${ }_{17}$ PA 656a8. See e.g., G. E. R. Lloyd, Science, Folklore and Ideology, Cambridge: Cambridge University Press, 1983, pp. 28-29. Cf. Aristotle, EN $1141 \mathrm{a} 33 \mathrm{f}$.

${ }^{18}$ GA 736b29 f., Cf. GA 732a3 f.

${ }^{19}$ And indeed, to a limited extent it is true of all things: EN $1153 \mathrm{~b} 32$.

${ }^{20}$ De an. 415a29 f. On the eternality of biological species for Aristotle, see James G. Lennox, 'Are Aristotelian Species Eternal?' in Allan Gotthelf (ed.), Aristotle on Nature and Living Tbings, Pittsburgh: Mathesis Publications, 1985, pp. 67-94.

${ }^{21}$ Metaph. 980b22. On this passage see, e.g., Ömer Orhan Aygün, 'On Bees and Humans: Phenomenological Explorations of Hearing Sounds, Voices, and Speech in Aristotle', Epoché (2013) 17, pp. 337-50. Contrast HA $627 \mathrm{a} 15$ where they seem to 'rejoice' in hearing certain noises.

${ }^{22} \mathrm{H} A$ 488b15, 611a16, 612a3, 612b1, GA 753a12-14. Aristotle also says that blooded animals (so excluding bees) whose blood is thin and cold are more phronimos at $P A$ 648a8. People, though, are the most phronimos of all animals: GA 744a30. 
${ }^{23}$ PA 648a6. They also live longer than some blooded animals: Aristotle, On Length and Shortness of Life, 466a4, cf. Aristotle, On Youth, Old Age, Life and Death, and Respiration (hereafter Jwv.) 475a4, HA 554b6.

${ }^{24} \mathrm{P} A 650 \mathrm{~b} 25 \mathrm{f}$. On the later history of ants as exemplars of moralizing qualities and their place in the hierarchy of intelligence see Charlotte Sleigh, Six Legs Better: A Cultural History of Myrmecology, Baltimore: Johns Hopkins University Press, 2007.

${ }^{25}$ Aristotle, Physics (hereafter Phys.) 199a23.

${ }^{26}$ De an. 428a11.

${ }^{27}$ HA 488a 7 f. C.f., HA 589a2 and also Aristotle, Politics (hereafter Pol.) 1253a7 where man is said to be 'more political' than bees and other animals. On bees as political animals, see Carla Nicolaye, 'Sed inter omnia ea principatus apibus: Wissen und Metaphorik der Bienenbeschreibungen in den antiken Naturkunden als Grundlage der politischen Metaphor vom Bienenstaat', in Engels and Nicolaye, op. cit. (11) pp. 114-37; David J. Depew, 'Humans and Other Political Animals in Aristotle's 'History of Animals', Phronesis (1995) 40, pp. 156-81; John M. Cooper, 'Political Animals and Civic Friendship', in Günther Patzig (ed.), Aristoteles Politik', Göttingen: Vandenhoeck \& Ruprecht, 1990, pp. 221-41; Wolfgang Kullmann, 'Der Mensch als politisches Lebewesen bei Aristoteles', Hermes (1980) 108, pp. 419-43.

${ }^{28} \mathrm{HA} 625 \mathrm{~b} 3$.

${ }^{29} \mathrm{HA} 614 \mathrm{~b} 18 \mathrm{f}$.

${ }^{30} \mathrm{H} A$ 627a27. Some modern commentators have tried to see in this passage an anticipation of von Frisch's discovery of the bees' waggle dance but the evidence is weak. On the dance of bees, see Tania Munz,The Dancing Bees: Karl von Frisch and the Discovery of the Honeybee Language, Chicago: University of Chicago Press, 2016.

${ }^{31}$ HA $627 \mathrm{~b} 10$.

32 HA 625b18.

${ }^{33} \mathrm{HA}$ 553b19, 625a16, 629a14 f.

${ }^{34} \mathrm{HA} 626 \mathrm{~b} 11 \mathrm{f}$.

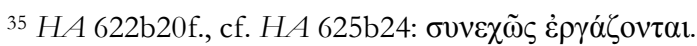

${ }^{36} \mathrm{H} A$ 623b22.

${ }^{37}$ HA 626a25, HA 596b15.

${ }^{38} \mathrm{H} A$ 554b3, 625a17, 626a14, 626b14, 615b16, etc.

${ }^{39} \mathrm{H} A$ 627a14. C.f. $627 \mathrm{a} 31 \mathrm{f}$.

${ }^{40}$ The literature here is vast and much of it centres on the Prime Mover and Metaphysics $\Lambda$. See e.g., Fabienne Baghdassarian, La question du divin chez. Aristote: Discours sur les dieux et science du principe, Leuven: Peeters, 2016; Stephen Menn, The Aim and the Argument of Aristotle's Metaphysics, https://www.philosophie.hu-

berlin.de/de/lehrbereiche/antike/mitarbeiter/menn/contents [accessed 25 February, 2019]; Stephen Menn, 'Aristotle's Theology', in Christopher Shields (ed.), The Oxford Handbook of Aristotle, Oxford, Oxford University Press, 2012, pp. 422-64; Jean-Baptiste Gourinat, 'Le premier moteur selon Physique, VIII et Métaphysique, $\Lambda$ : Physique et philosophie première', in M. Bonelli (ed.), Physique et métaphysique chez. Aristote, Paris: Vrin, 2012, pp. 175-206; Enrico Berti, 'Y a-t-il une théologie d'Aristote?' in Luc Langlois and Yves Charles Zarka, eds., Les philosophes et la question de Dieu, Paris: Presses Universitaires de France, 2006, pp. 55-71; Barbara Botter, Dio e divino in Aristotele, Sankt Augustin: Academia Verlag, 2005; Michael Frede and David Charles (eds.), Aristotle's Metaphysics Lambda, Oxford: Oxford University Press, 2000. Coming at the question of divinity in Aristotle from very different angles, in some ways perhaps closer to my own approach here, are Matthew D. Walker, Aristotle on the Uses of Contemplation, Cambridge: Cambridge University Press, 2018; Richard Bodéüs, Aristote et la théologie des vivants immortels, Paris: Belles Lettres, 1992.

${ }^{41}$ Aristotle, On the Heavens (hereafter Cael.) 286a8-9. C.f. Cael. $270 b 10$ and Cael. 1.9.

${ }^{42}$ Planets: e.g., Cael. 279b1, 288a4, 292b22, 292b32, De an. 405a32, Metaph. 1074a30. Cosmos: Cael. 279a11, $286 a 11$.

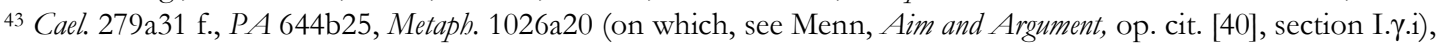
Metaph. $1064 \mathrm{a} 37$.

${ }^{44}$ Prime mover: Aristotle, Movement of Animals (hereafter IA) 700b34. First cause(s): Cael. 279a30, GA 732a3 f., EE 1248a27. First philosophy: Metaph. 1026a18. First principles: Cael. 284a4, GA 731a24 f., EN 1102a4.

${ }^{45}$ GA 761a2-5.

${ }^{46} G A 759 \mathrm{~b} 27 \mathrm{f}$.

${ }^{47}$ Also compare GA 741a33-37 where he speculates, again apropos of the erytbrinus, that it may be possible for an animal that has only females (not a combination of the female and the male, as with bees) to reproduce: $\varepsilon^{\prime} \delta^{\prime}$ है $\sigma \tau \imath \tau 1$

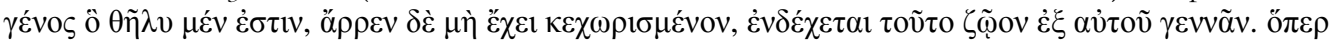

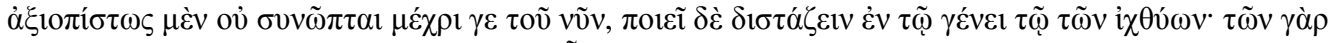

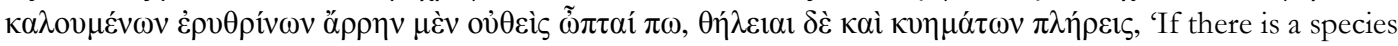
which is [entirely] female and has no [distinct] male, it may be possible for this animal to generate from itself. This has not been reliably observed thus far, at any rate, but there is [an example] among fish that gives us pause, for in the so-called erythrini, no male has yet been observed, and the females are full of eggs'.

48 Illustrations by Jay Stephens (jaypopgun@yahoo.ca), commissioned by the author.

49 GA 760a12-14 and a26-b2. 
${ }^{50} \dot{\alpha} v \alpha \dot{\lambda} \sigma \gamma o \varsigma$ is frequently used for proportionality in Aristotle.

51 Cael. 268a10.

52 The minor exceptions are: (1) Aristotle, Sense and Sensibilia, 439a31 where he remarks in passing that a Pythagorean term for colour seems to agree with a point he himself makes. (2) Aristotle, Posterior Analytics (hereafter APo.) 94b33 is noncritical but clearly hypothetical. (3) At Phys. 222b18, he cites with approval an otherwise unknown and likely fictitious Pythagorean named 'Paron'. For what it is worth, Aristotle cites this Paron as saying that 'time is very stupid', which is metaphorical at best and inconsequential in any case. (Paron's name is simply the Greek participle for 'being present': see Walter Burkert, Weisheit und Wissenschaft: Studien zu Pythagoras, Philolaus und Platon, Nürnberg: Verlag Hans Carl, 1962; 'Paron' is entirely omitted from the most recent comprehensive collection of Presocratic material [André Laks and Glenn W. Most (eds.), Early Greek Philosophy, 9 vols., Cambridge, MA: Harvard University Press, 2016]). (4) At Cael. 284b7, Aristotle more or less agrees with the point the Pythagoreans make, at least in outline, although he thinks his own version is 'better' (c.f., 285a10, b25). For similarly qualified support, see Aristotle, Meteorology (hereafter Meteor.) $986 \mathrm{~b} 1$ and possibly EN $1186 \mathrm{~b} 30$.

${ }^{53}$ Cael. 268b24-26.

${ }^{54}$ Bifurcations, where there are said to be two different aspects to a thing or two different ways of conceiving of an idea are rarer and, in general, individually less central to Aristotle's philosophy. There are some very important quadripartite divisions, to be sure (elements, qualities, causes), but not nearly as numerous.

55 Appetites LA 700b22, EE 1223a27; animal and cosmic parts Cael. 284b20; IA 704b20; animal reproduction passim, but esp. in $\mathrm{HA}$ - - this schematization is remarkably pervasive; animal parts Juv. 468a13; argument Rh. 1358a38; attributes Topics (hereafter Top.) 115a16; audience Rhetoric (hereafter Rh.) 1358a37; condensed bodies Meteor. $347 \mathrm{~b} 12$. ${ }^{56}$ Coming-to-be Phys. 190b28; composition of animal parts PA 646a12; causes Meteor. 1069b32; change, aspects, Aristotle, On Generation and Corruption (hereafter GC) 322b6-328b29; change, kinds Phys. 224a19 f., or differently at Meteor. 1067b19; channels from eye HA 495a13; choice EN 1104b30; contempt Rh. 1378b13; commerce Pol. 1258b22; constitution EN 1160a31; courts of law Pol. 1300b15; craftsman Pol. 1282a3.

${ }^{57}$ Deception Rh. 1378a9; deduction Prior Analytics (hereafter APr.) 25b27, $41 \mathrm{~b} 36$ f. et pass.; demonstration, kinds APo. 75a39; dimensions passim; dispositions EN 2.6-8; education Pol. 1342b34; elements Cael. 277b13; emotions Rh. 1378a24; excellence Pol. 1332a40.

${ }^{58}$ Friendship EN 1156a7, 1162a34, etc.; good EN 1098b13, Pol. 1323a25; government appointments Pol. 1300a10; government branches Pol. 1297b41; government forms Pol. 1288a32; government equality Pol. 1294a19; mixed government Pol. 1294a35; growth GC 321a18.

${ }^{59}$ Happiness EE 1214a31; harms EN 1135b11; head PA 686a19; heart actions Juv. 479b17; heart cavities HA 496a4 et pass.; heaven Cael. 278b10; homonymy Sophistical Refutations 166a17; insect bodies HA 531b25; insect development GA 759a2; imitation Poetics (hereafter Po.) 1447a16; justice EE 1241b33.

${ }^{60}$ knowing APr. 67b4; life EN 1095b17, EE 1215a35; love EN 1155b27; luck Rh. 1361b39; magistrates Pol. 1323a6; moral states EN 1145a16; movement aspects Phys. 227b24, De an. 433b12, Phys. 236b2, Phys. 266a13, Phys. 256b14, Phys. 262a19; movement kinds Phys. $225 b 7$ f., Cael. 268b26, Cael. 310a23, Meteor. 1068a9, et pass.; mover Phys. 243a8; music Pol. 1339b14; non-being Meteor. 1069b27; nutririon De an. 416b20.

${ }^{61}$ Opposition APr. 63b25; orator Rh. 1378a8; people Pol. 1295b2; perceptibility De an. 418a8; perception De an. 428b25; persuasion Rh. 1356a2; physics Phys. 198a29; poetry Po. 1447b25; offices Pol. 1309a33; power Pol. 1.3; presentation Po. 1460b9; problems Top. 105b19; 'productive' Rh. 1362a31.

${ }^{62}$ Relaxation Pol. 1339a20; rhetoric ends Rh. 1358b20; rhetoric forms Rh. 1.3; rhetoric grades Rh. 1359a7; rhetoric temporal horizons Rh. 1358b13; sameness Top. 103a7; vividness $R h .1410 \mathrm{~b} 35$; speeches Rh. 1403 a34.

${ }^{63}$ Soul characteristics De an. 405b10; soul critical faculties $L A$ 700b19; soul functions GA 2.3; soul parts EN 1139a17; soul variables EN 1105b19; stasis Pol. 1302a19; substance kinds Meteor. 1069a30, 1070a9; substance meaning De an. 414a14; sutures HA 516a18.

${ }^{64}$ Theoretical knowledge Meteor. 1064b1; tile Cael. 306b5; toes HA 498b1; Topics Top. 101a25; tyrants Pol. 1314a15; voice Rh. 1403b30; 'voluntary' EE 1224a4; wrongdoing Rh. 1368b3.

${ }^{65}$ Cael. 268a19.

${ }^{66}$ Meteor. 374b30 f. One may want to cavil about the specific division here, but cross-cultural, cross-linguistic, and cross-temporal colour categories are notoriously foreign looking. For present purposes let us simply grant him the categories as given.

${ }^{67}$ Pol. $1326 a 32$

68 Aristotle's point is aimed in the first instance at the qualities of the good state, as the context makes clear.

${ }^{69}$ GA 760b28.

${ }^{70}$ Metaph. 1078a36-b5. I warmly thank Giora Hon for bringing my attention to the importance of this passage in the context of the present argument.

${ }^{71}$ This last word might be translated as 'specificity' or even 'limit'. For the meaning of symmetry, in this context, see Giora Hon and Bernard R. Goldstein, From Summetria to Symmetry: The Making of a Revolutionary Scientific Concept, New York: Springer Verlag, 2008.

${ }^{72}$ Cael. 268 a10.

${ }^{73}$ GA 760a12-14 and a26-b2. 